\title{
IGREJA CATÓLICA E DITADURA CIVIL-MILITAR: algumas palavras sobre a experiência da Arquidiocese de Olinda e Recife
}

\author{
Severino Vicente da Silva*
}

RESUMO: O artigo pretende fazer uma reflexão sobre a atuação da Igreja Católica na Arquidiocese de Olinda e Recife no contexto da ditadura civil-militar que ocorreu no Brasil entre os anos de 1964 e 1985, período que coincide com o governo arquidiocesano de Dom Hélder Câmara, que teve sua atuação na defesa dos Direitos Humanos, os quais foram definidos pela ONU em 1948, mas foi entendida como de oposição aos militares no poder.

PALAVRAS-CHAVE: Igreja Católica; Ditadura civil-militar; Memória social.

\section{Catholic church and civil-military dictatorship: a few words about the experience of the Archdiocese of Olinda and Recife}

ABSTRACT: The article intends to reflect on the work of the Catholic Church in the Archdiocese of Olinda and Recife in the context of the civil-military dictatorship that occurred in Brazil between 1964 and 1985, a period that coincides with the archdiocesan government of Dom Hélder Câmara, in the defense of Human Rights, defined by the UN in 1948, but was understood as opposing the military in power.

KEYWORDS: Catholic Church; Civil-military dictatorship; Social memory.

\section{Iglesia católica y ditadura civil-militar: algunas palabras sobre la experiencia de la Arquidiócesis de Olinda y Recife}

RESUMEN: El artículo tiene la intención de hacer una reflexión sobre la actuación de la Iglesia Católica en la Arquidiócesis de Olinda y Recife en el contexto de la dictadura civil-militar que tuvo lugar en Brasil entre los años 1964 y 1985, período que coincide con el gobierno arquidiocesano de Mons. Hélder Câmara, que actuó en la defensa de los Derechos Humanos, definidos por la ONU en 1948, pero fue entendida como de oposición a los militares en el poder.

PALABRAS CLAVE: Iglesia católica; Dictadura civil-militar; Memoria social.

\footnotetext{
*Doutor em História pela Universidade Federal de Pernambuco. Atualmente é professor Associado do Departamento de História da mesma universidade, membro do Instituto Histórico de Olinda, Membro da Comissão de Estudos de História da Igreja na América Latina - CEHILA. Contato: Av. da Arquitetura, s/n, $\mathrm{CFCH}, \quad 11^{\circ}$ Andar, Cidade Universitária, CEP: 50740-550, Recife-PE, Brasil. E-mail severino.vicente@gmail.com. ORCID: http://orcid.org/0000-0001-8911-1409.
} 
A segunda metade do século XX é bastante rica em eventos que apontaram para mudanças na sociedade brasileira, mudanças que vinham ocorrendo como parte da Guerra Mundial, tais como a emergência de novos países asiáticos e africanos, a crise da consciência dos europeus que se viram como que em julgamento pelos sucessos das mudanças ocorridas nos séculos anteriores e a necessidade de rever o comportamento das sociedades e instituições nesses novos desafios, especialmente o confronto entre duas grandes ideologias, materializadas na política de duas forças potentes. Nesse embate também se encontra a Igreja Católica Romana, tradicional aliada sociopolítica das camadas bem aquinhoadas do Brasil. $\mathrm{Na}$ segunda metade do século, a Igreja viu-se dividida e exposta em sua divisão, no centro de um confronto que ela tomou como seu. A Guerra Fria, a consciência da exploração de parte da sociedade por outra parte, serve de quadro para o drama vivido e escrito por clérigos e leigos, no campo sociopolítico brasileiro.

Já são numerosos os estudos sobre a atuação da Igreja Católica durante o período da ditadura civil-militar instalada no ocaso de março e aurora de abril do ano de 1964 e dita terminada em 1985. Podemos, então, pensar na obra de Roberto Romano, Loureiro Botas ${ }^{1}$, Márcio Moreira Alves ${ }^{2}$, Kenneth Serbin ${ }^{3}$, Mainwaring Scott $^{4}$, Carlos Bresser-Pereira ${ }^{5}$, José Oscar Beozzo ${ }^{6}$, Jailton $\mathrm{Paz}^{7}$, entre outros. Recentemente têm aparecido reflexões que não consideram ditadura o que ocorreu entre os anos de 64 a 69 e os anos que se seguem ao ano de 1979, restando apenas uma década de ditadura, de 1969 a $1979 .{ }^{8}$ Em pronunciamento recente, o historiador Boris Fausto não reconhece tal divisão, preferindo usar o termo ditadura para todo o período de 1964 a $1985^{9}$.

O ano de 2014, cinquentenário do Golpe, prestou-se para um reencontro com os acontecimentos e tensões daquele período, e, como sói acontecer, é tempo de fazer novas leituras do passado. As Comissões da Verdade instaladas em vários níveis de governo, desde uma Comissão Nacional, outras em alguns Estados da União e até mesmo em municípios, têm prestado esclarecimentos os mais diversos, trazido novos documentos que, ora afirmam o que já se sabia, ora vem declarar inócuas crenças como o assassinato de Juscelino Kubitschek. ${ }^{10}$ Foi necessária muita atenção aos historiadores para não serem dominados pelas paixões partidárias que sempre ocorrem nessas releituras do passado. ${ }^{11}$ Cada geração busca entender o que ocorreu no passado que formou o seu presente, e, a cada nova geração, novos documentos surgem para confirmar, negar ou pôr em dúvidas as explicações e entendimentos que então se tem daquilo que parece ter sido o passado, jamais visto em sua totalidade. Afinal, sabemos que não existe uma só memória, e a nossa memória ou a do grupo ao qual pertencemos não deve, necessariamente, ser a memória de todos. Essas emoções que envolvem os homens 
também atingem os historiadores. As primeiras linhas da introdução de A Revolução Francesa em questão, dão-nos uma ideia da dificuldade em definir um acontecimento, uma revolução, por mais que ela tenha sido estudada: Para os historiadores, hoje em dia, a Revolução Francesa não é mais, de modo algum, o que era antes. E, no entanto, eles dispunham há muito tempo de uma explicação sedutora. ${ }^{12}$ Esta é uma situação que se apresenta em todos os trabalhos historiográficos e também ocorre no que concerne aos estudos da participação das igrejas nos eventos sociopolíticos daquele período de nossa história recente, mas, de certa forma, já esquecido por alguns dos que viveram e desconhecido pelos que nasceram no final do século XX e no início do atual século.

As análises sobre o comportamento da Igreja nos embates sociais referentes ao período do regime autoritário ou ditatorial recente foram iniciadas ainda durante a ditadura ou em seus estertores. Afinal procurava-se entender como e por quê uma instituição que sempre foi acoimada de conservadora ao longo da formação do Brasil, durante aquele tempo de espoliação das liberdades brasileiras, veio a assumir posturas então descritas como "progressistas". Aliás, essa busca de entendimento podia ser encontrada antes do golpe de 1964, pois, antes daquele evento, a Igreja já vinha adotando algumas posturas desusadas. Nos anos cinquenta, a Igreja Católica, ou parte dela, pôs em debate a Reforma Agrária no encontro da Ação Católica Agrária, ocorrida na diocese de Campanha, MG, com a publicação da Carta Pastoral "Conosco, sem Nós e contra Nós se fará a reforma rural", Carta Pastoral de Dom Inocêncio Engelke, sendo este o primeiro documento oficial da Igreja Católica Romana que trata da questão rural e agrária; e ela foi prontamente respondida com o livro Reforma Agrária: questão de consciência ${ }^{\mathbf{1 3}}$, por setores católicos mais tradicionais e infensos às mudanças do tempo. Mas cabe lembrar que naquele encontro era notória a ausência de camponeses, pois se tratava de um evento da chamada Ação Católica Rural, mais voltada para os proprietários das terras, daí então o título do documento mencionar "conosco e contra nós", os proprietários. Era ainda a Igreja nas varandas das fazendas. Anos depois, a presença da Igreja Católica nas áreas rurais, não mais nas varandas das casas grandes e das fazendas, gerou muitas discussões e interpretações. Uma dessas interpretações foi que, pelo temor de perder os camponeses, a Igreja viu-se obrigada a tornar-se mais ativa no campo, onde os comunistas já se infiltravam, como havia dito a pastoral de Dom Inocêncio Engelke. Mais tarde a sociologia e a experiência histórica mostraram também a chegada dos evangélicos no campo, acirrando a concorrência pela adesão das almas. Ora, pode-se inferir desse fato que, apesar de a Igreja Católica Romana ser apontada como uma unidade, como o Corpo Místico de Cristo, o seu percurso histórico demonstra que essa unidade doutrinária não corresponde a 
uma unidade social e, para tal entendimento, basta citar episódios como a Questão das Investiduras, na Idade Média, O Cisma do Oriente, a Reforma Luterana e muitos outros momentos. No Brasil, a historiografia dedicou-se pouco ao estudo da presença da Igreja na construção da sociedade, como é notório na obra de Edgar Carone, entre outros, que quase não menciona a Igreja em sua série de estudos sobre a República, ${ }^{14}$ consagrando uma visão unitária da Igreja, não percebendo as tensões que ocorriam no seu interior. Tais tensões vieram à tona, acompanhando a compreensão da complexidade social e histórica da realidade brasileira, nos anos mais recentes, após a publicação dos estudos feitos pela Comissão Estudos da História da Igreja na América Latina. ${ }^{15}$

No início da segunda metade do século XX, a participação da Igreja ampliava-se no campo, incentivando a criação de sindicatos rurais ${ }^{16}$. Na Arquidiocese de Olinda e Recife foi criado, pelo então arcebispo Dom Carlos Coelho, o Serviço de Orientação Rural - SORPE, no mesmo caminho indicado por Dom Eugênio Sales, bispo auxiliar de Natal. Além do histórico abandono das comunidades de agricultores, havia a ocorrência de uma longa seca no início daquela década, que veio a atingir até mesmo o Agreste Setentrional e a Mata Norte de Pernambuco, ensejando uma migração na direção da capital de Pernambuco, o que provocou a poesia de João Cabral de Melo Neto, Morte e Vida Severina. Por conta das mudanças internacionais, ${ }^{17}$ também o Estado brasileiro teve que modernizar-se, o que fez com a realização do Plano de Metas de Juscelino Kubitschek, porém sem considerar o que ocorria nos sertões do Nordeste. Apenas após a posse é que o presidente viu-se forçado a criar a Superintendência do Desenvolvimento do Nordeste - SUDENE. Ademais, o Brasil começava a deixar de ser um país populacionalmente agrário, por razões múltiplas e geradas pelas contradições internacionais e internas, tendia a urbanizar-se. E era uma urbanização sem planejamento. Enquanto as longas estiagens forçavam camponeses nordestinos a migrar para o Sudeste, as grandes obras atraíam essa população com a promessa de melhoria significativa de vida. Assim cresceram as cidades.

A urbanização descontrolada em um país que não criara meios para atender às demandas de sua população gerou a favelização das massas migrantes nas cidades-polos dessa modernização industrial. Em algumas dessas cidades, especialmente nas capitais dos estados, mas apenas nelas, ${ }^{18}$ a Igreja Católica viu-se forçada a buscar a compreensão do fenômeno, e o fez auxiliada pela experiência da Ação Católica Brasileira ${ }^{19}$, renovada a partir de 1949 , quando foi escolhido para ser Assistente Nacional o então Monsenhor Hélder Câmara. A Ação Católica Brasileira deixou de seguir o modelo italiano ${ }^{20}$, implantado nos anos vinte, para assumir as características franco-belga, seja dizer, o modelo criado pelo padre José 
Cardjin, o idealizador da Juventude Operária Católica. Quem mais aproveitou essa nova assistência foi a Juventude Universitária Católica - JUC - que, aos poucos, veio a assumir por anos a presidência da União Nacional dos Estudantes, com Aldo Arantes no biênio 1961-62, José Serra, no biênio 1963-64, e Marcos Brandt nos anos 1965-66, sendo também escola de formação de lideranças e assessorias aos bispos nos diversos regionais da $\mathrm{CNBB}$, que havia sido fundada em 1952, sob a liderança do já então bispo Dom Hélder Câmara. Como bispo auxiliar do Rio de Janeiro, ao tempo que frequentava os ambientes oficiais e políticos do Distrito Federal, Dom Hélder Câmara inovara ao promover a urbanização das favelas próximas da praia de Copacabana ${ }^{21}$, e promovia a participação da $\mathrm{CNBB}$ nos debates que geraram a criação da SUDAN e da SUDENE. A criação de sindicatos sob a liderança da Igreja na zona rural, que estava ocorrendo sob a proteção do episcopado, foi vista pelos concorrentes da Igreja como uma maneira de impedir a conquista dos camponeses pelos comunistas e anarquistas que também estavam chegando ao campo, seguindo orientação de seus partidos. Afinal, a recente Revolução Chinesa não foi feita por operários de fábricas, mas pela massa de camponeses liderados por Mao Tsé-Tung, e a revolução liderada por Fidel Castro, em Cuba, não foi realização do proletariado.

A criação de novas dioceses nas circunscrições eclesiásticas nos indica o processo de ocupação dos espaços pela população, é uma maneira de reorganização das relações da Igreja com os seus fiéis, e essa aproximação pode ser decorrente do temor de perder espaços políticos. Na circunscrição eclesiástica de Pernambuco, em 1956, foi criada a Diocese de Afogados da Ingazeira, no Sertão Pernambucano, após um período de grande estiagem que pôs a região em ebulição e no foco nacional. Ainda em Pernambuco, a situação na Zona Canavieira, na Mata Sul, vinha se tornando mais tensa, resultado da modernização conservadora, também ocorreu a criação da Diocese de Palmares no ano de 1962, que pode ser vista como uma preocupação com a afirmação da Igreja Católica naquela região. A diocese de Palmares foi criada a pedido do Arcebispo de Olinda e Recife, Dom Carlos de Gouveia Coelho, também criador do Serviço de Orientação Rural de Pernambuco - SORPE, cuja direção foi confiada ao padre Paulo Crespo, então vigário de Jaboatão. ${ }^{22}$ Também havia ao sul do Recife e Jaboatão a participação do padre Antonio Melo, vigário do Cabo de Santo Agostinho, que agia de maneira independente do SORPE, embora tenha dele participado nos primeiros anos daquela entidade diocesana. Também na cidade do Cabo de Santo Agostinho, a criação de um polo industrial promoveu a formação de um núcleo da Juventude Operária Católica, que contava com o acompanhamento do padre Moisés Lindoso. ${ }^{23}$ 
Dom Carlos Coelho, um dos fundadores da CNBB, morreu a sete de março de 1964, estando a diocese sem arcebispo até 12 de abril, quando Dom Hélder tomou posse. ${ }^{24} \mathrm{~A}$ chegada de Dom Hélder Câmara, como a de todo novo bispo a uma diocese, ensejou anseios de mudanças, especialmente por parte dos católicos ${ }^{25}$ que acompanhavam o Concílio Vaticano II, no qual o novo arcebispo teve um desempenho bem visto por grande parte do episcopado europeu e norte-americano. Dom Hélder trazia consigo o simbolismo de ter sido o fundador da CNBB e seu Secretário Geral por muitos anos, além de ser visto como um exemplar modelo do episcopado que se desenhava nos documentos conciliares, um bispo atento aos "sinais do tempo". Esse novo tipo de bispo se anunciava já em seu discurso de posse ao nomear Jesus Cristo de Zé e Severino, nomes próprios das pessoas mais pobres da sociedade $^{26}$. Saindo direto do Vaticano para o Recife, Dom Hélder notou que a nova direção da $\mathrm{CNBB}^{27}$ não havia comentado os acontecimentos do início de abril, a Igreja Católica ainda não se pronunciara sobre o golpe de Estado autodenominado revolução. Diante da situação, foi articulada uma reunião de bispos e superiores religiosos na cidade de São Luís do Maranhão, arquidiocese para a qual Dom Hélder havia primeiramente sido indicado, antes da morte de Dom Carlos Coelho, e dessa reunião saiu um documento que analisava a conjuntura de então e posicionava parte do clero brasileiro. Embora não tenha sido um documento da CNBB, essa declaração passou a ser vista como a posição oficial da Igreja em relação ao movimento de 31 de março de 1964, e só foi publicado no final de maio daquele ano. Em sua primeira parte, o documento louva a ação dos militares por terem salvado o Brasil do abismo comunista e, na segunda parte do documento, os prelados chamam a atenção para que não sejam desrespeitados os direitos da pessoa humana, dos filhos de Deus, afirmando que a Igreja saberá tomar a defesa dos injustiçados. ${ }^{28}$ É este o quadro que se tem da Igreja nos momentos iniciais do período ditatorial.

Em 1962 algumas lideranças da Juventude Universitária Católica criaram a Ação Popular - AP - ${ }^{29}$ que mais tarde tornou-se Ação Popular Marxista-Leninista -APML - e, quando isso ocorreu, a CNBB os desautorizou como grupo católico, pois aderiram à luta de classe. A Igreja então perdeu parte da juventude que havia formado na década anterior. Esses jovens, como outros, foram perseguidos, foram exilados. Muitos dos que não aderiram ao marxismo-leninismo permaneceram atuando na área da educação popular e os líderes do movimento civil-militar, que se aboletaram no poder em 1964, sempre entenderam que os auxiliares leigos de Dom Hélder eram militantes da AP.

Como outros bispos, durante o Concílio Vaticano II Dom Hélder havia feito o Pacto das Catacumbas ${ }^{30}$ e era um entusiasta do II Encontro da Comissão Episcopal Latino-Americana - 
CELAM - em Medellín, na Colômbia, no ano de 1968. Este encontro tem sido visto como a atualização do Vaticano II para a América Latina e, sem dúvida, o documento dele emanado foi durante anos encaminhando a Igreja para a Opção pelos Pobres, mais tarde Opção Preferencial pelos Pobres ${ }^{31}$. Antes do encontro em Medellín, em preparação para ele, foram realizados estudos, estimulados pelos bispos em suas dioceses, sobre a realidade latinoamericana e a brasileira em particular, para servir de embasamento aos bispos naquela reunião episcopal.

As ações do novo bispo indicaram que ele continuaria, em Pernambuco, a atuação que lhe valera ser apodado de "bispo vermelho",32, pois sua ação estava mais próxima do povo mais simples, como no atendimento às vítimas da enchente de $1965 \mathrm{e}$, depois, na de 1975. O seu programa de Evangelização, iniciado no tempo do Advento de 1964, galvanizou a periferia do Recife com o movimento de evangelização Encontro de Irmãos ${ }^{33}$, protótipo das Comunidades Eclesiais de Base, usando a Rádio Olinda, então pertencente à arquidiocese e às Irmãs Paulinas. Enquanto o Encontro de Irmãos cuidava da formação e fortalecimento da fé, as enchentes e os deslizamentos dos morros abriram a senda para a formação social e política com a criação dos Conselhos de Moradores, provocando a formação de lideranças comunitárias. Este trabalho foi realizado pela Operação Esperança, que atuava nas periferias da cidade, como ocorreu em Nova Descoberta, Mangueira, Jordão, entre outros. A Operação Esperança $^{34}$ também atuou na área rural, pois Dom Hélder usou alguns dos prêmios recebidos para a compra de terras de engenhos e, depois de um processo de formação, transferir a propriedade para os moradores. As repercussões sociais desses trabalhos mereceram a prisão de alguns de seus militantes. No caso do Encontro de Irmãos, a prisão mais notada foi a de João Francisco de Souza ${ }^{35}$, que era um dos coordenadores do movimento. No mesmo ano de 1972 ocorreu a prisão de pessoas que atuavam nos Conselhos de Moradores $^{36}$, e ainda jovens ${ }^{37}$ com atuação no Conselho de Moradores de Nova Descoberta e na Pastoral de Juventude da Arquidiocese.

A ação de Dom Hélder na sua arquidiocese foi encaminhando-se para a defesa dos direitos humanos, e em 1968 foi lançado o movimento PRESSÃO MORAL LIBERTADORA tendo por chão a prática da não violência, tomando Mahatma Gandhi e Martin Luther King como paradigmas de sua ação. Era a celebração dos vinte anos da Declaração Universal dos Direitos Humanos, da Organização das Nações Unidas. Assim começava o enfrentamento com o Estado e as torturas que começavam a serem praticadas nos porões dos quartéis. As manifestações do movimento Pressão Moral Libertadora realizaram-se em ambientes fechados, como a ditadura permitia naquele momento. O lançamento do movimento ocorreu 
no auditório do Colégio São José, na Avenida Conde da Boa Vista e outra manifestação no pátio interno da Matriz do Bom Jesus do Arraial, próxima ao Sítio da Trindade. ${ }^{38}$ Foi nesse ano que ocorreu a prisão e expulsão dos padres Oblatos de Maria, de nacionalidade norteamericana, ${ }^{39}$ que trabalhavam na Paróquia do Jordão. Em maio de 1969 foi sequestrado e assassinado o Padre Antonio Henrique de Pereira Neto ${ }^{40}$, que desenvolvia suas atividades com jovens de classe média e ensinava no Colégio Marista do Recife ${ }^{41}$. O Assassinato do padre Antonio Henrique ocorreu um mês após o atentado contra o estudante Cândido Pinto, presidente da União dos Estudantes de Pernambuco ${ }^{42}$. O assassinato do padre Henrique deve ser entendido como uma maneira de atingir o Arcebispo indiretamente, pois atingi-lo diretamente causaria uma questão de política internacional. Essa ação de ataque a Dom Hélder continuou e chegou ao seu clímax nos anos de 1972 e 1973, momento de maior ação das forças repressivas sobre todos os movimentos, armados ou não, que desafiavam o regime.

No dia Primeiro de maio de 1967, dois anos antes do assassinato do Padre Antonio Henrique, a Ação Católica Operária ${ }^{43}$ lançou, no Recife o documento NORDESTE DESENVOLVIMENTO SEM JUSTIÇA, com críticas à política econômica de arrocho salarial que estava levando os trabalhadores à desesperança. Como se pode observar na leitura de jornais, é a vasta atuação da Igreja que preocupa o Regime e o leva a pressionar quem o contesta. Exemplo disso foi a atuação do vereador recifense Wandekolke Wanderley que acusa Dom Hélder de ser comunista ${ }^{44}$, e o deputado Antônio Correia de Oliveira que acusa Dom Hélder de não ter Deus, logo após ele ter recebido o título de Cidadão Pernambucano. ${ }^{45}$ Em 03 de outubro de 1967, o Jornal do Brasil publica nota na qual Gilberto Freyre acusa Dom Hélder de aliar-se ao comunismo internacional. A pressão sobre os católicos não os levou ao silêncio. Em 1970, a Ação Católica Operária lançou um dos fortes manifestos críticos à ditadura e à sua política econômica: NORDESTE: O HOMEM PROIBIDO. Documento que foi publicado como apoio da arquidiocese, valeu a prisão do padre Romano Zeffery, Assistente da ACO, e a invasão da sede da ACO, na Rua Gervásio Pires. Nessa oportunidade os agentes da ditadura levaram livros da Livraria da ACO que funcionava na parte frontal da mesma. O padre Romano ficou à frente da entidade até a sua morte, em $1985 .^{46}$ Atualmente a ACO denomina-se Movimento dos Trabalhadores Cristãos - MTC.

Momento grave e que trouxe consequências para a vida da Igreja local, nacional e também para o país foi o discurso proferido em Paris, em janeiro de 1971, no Palácio dos Esportes. Naquela oportunidade, Dom Hélder tornou público que a prática de torturas ocorria nos porões do Regime Militar, embora as autoridades sempre negassem e a sociedade não quisesse tomar conhecimento. Após o discurso no Palácio dos Esportes se fortaleceu a ordem 
de não mencionar o nome do Arcebispo de Olinda e Recife em qualquer meio de comunicação, inclusive foi apresentado, em rede nacional, programa com objetivo de desqualificar o arcebispo de Olinda e Recife, acusando-o de ser comunista. Era a tentativa de silenciar a voz dos que não podiam falar. No ano de 1972, por suas ações na defesa dos Direitos Humanos, Dom Hélder foi indicado para receber o prêmio Nobel da Paz, e o governo tomou iniciativas que impediram o recebimento da honraria, pois a entendiam como uma condenação internacional ao que os militares estavam tornando o Brasil. ${ }^{47}$ Também foi notória a ação do bispo de Diamantina, MG, Dom Sigaud e Proença em palestras na Europa buscando enlamear a vida de Dom Hélder. Dois anos depois, entidades comprometidas com a defesa dos Direitos Humanos criaram e concederam a Dom Hélder o Prêmio Popular da Paz, na Noruega e Alemanha.

Se no ano de 1972 muitos que estavam militando na Operação Esperança, no Movimento de Encontro de Irmãos ou na Pastoral da Juventude ${ }^{48}$ foram presos e torturados, em maio de 1973, a Igreja do Nordeste 2 publica o documento EU OUVI OS CLAMORES DO MEU POVO, documento assinado por treze bispos ${ }^{49}$ e cinco superiores religiosos. A repercussão do documento foi intensa, interna e externamente. A Igreja Católica no Brasil sempre utilizou a publicação de cartas pastorais para comunicar e debater questões importantes para a formação dos fiéis. Estava em curso a retomada desta prática de comunicação dos bispos com suas igrejas, superando os limites da censura dos meios de comunicação. Assim, "Em 1971, por exemplo, tivemos, em 12 de novembro de 1971, a publicação da carta pastoral de Pe. Pedro Casaldáliga (dias depois ordenado bispo de São Félix do Araguaia), intitulada "Uma Igreja da Amazônia em conflito com o latifúndio e a marginalização social". Época em que também apareceu o documento "Y-Juca Pirama o Índio, aquele que deve morrer", assinado pelos bispos da região Extremo-Oeste do Brasil, entre os quais Dom Pedro Casaldáliga e Dom Balduíno, a denunciarem, com coragem, que em todo o país se constatam episódios de invasão e de gradativo esbulho das terras dos índios, em flagrante agressão aos seus direitos, em razão do que, mais do que sentindo-se ameaçados, tais agressões já estavam efetivamente em curso." ${ }^{50}$ Convém lembrar o assassinato do padre Bosco Burnier em 1976. ${ }^{51}$

Incidente que chama atenção em 1980 é a prisão e expulsão do vigário da paróquia de Ribeirão, da Diocese de Palmares. Convidado pela prefeitura local para celebrar missa especial nas festividades de comemoração da Independência do Brasil, o padre Vito Miracapilo recusou-se, lembrando que há missas na sua matriz e, como no Brasil pratica-se o estado laico, não se sente obrigado a celebrar em um evento oficial ${ }^{52}$. A intervenção do 
político Severino Cavalcanti acusando o padre de origem italiana de estar solapando os sentimentos de brasilidade levou o caso até a expulsão do sacerdote, em um momento de já declínio da ditadura. Por louvar a atitude do colega Vito Miracapilo em um hino litúrgico, o vigário da paróquia do Morro da Conceição, padre Reginaldo Veloso ${ }^{53}$, também sofreu prisão e processo. Interessante é lembrar que o Arcebispo Dom Hélder Câmara sempre recusou participar de cerimônias semelhantes, mas política e marotamente, sempre agendava viagens naquele período, deixando que as celebrações litúrgicas em tais solenidades fossem assumidas pelos capelães militares, evitando confrontos diretos desnecessários, ao mesmo tempo que marcava suas posições.

A Arquidiocese de Olinda e Recife criou, em 1977, a Comissão de Justiça e Paz ${ }^{54}$ e ela agiu na defesa dos direitos habitacionais da população, forçando uma melhoria na política habitacional da cidade e do estado com a criação do Plano de Regularizações de Áreas de Interesse Social - PREZEIS, porém, como nos habituamos a entender política apenas quando falamos de partidos ou facções, a Comissão de Justiça e Paz só vem sendo mencionada quando trata da defesa de presos políticos. Mas a constituição da Comissão de Justiça e Paz foi quase um imperativo do Concílio Vaticano II, do Sínodo dos Leigos e do entendimento das encíclicas sociais, e é seu entendimento de que não haverá paz sem justiça social, como ensina João XXIII em suas cartas Mater et Magistra e Pacem in Terris, bem como a Populorum Progressio de Paulo VI. Para os pontífices, a paz não se define apenas pela ausência de guerras mas pelo respeito a todos os direitos da pessoa humana, de todos os homens e do homem todo. Interessante é que foi a defesa da Comissão de Justiça e Paz, quando seu substituto, Dom José Cardoso Sobrinho, não mais a reconhece como parte da arquidiocese, que levou Dom Hélder ao silêncio. ${ }^{55} 56$

Ao término do governo do general Garrastazu Médici (1969-1974), o regime militar apresenta estafa e sente que devia sair da cena principal da política. É tempo de Diálogos na sombra. ${ }^{57}$ Inicia-se um processo para a superação dos tempos de chumbo, dá-se início ao tempo da longa distensão, que acompanhará os governos dos dois últimos generais no poder: Ernesto Geisel (1974-1979) e João Batista Figueiredo 1979 -1985). Aos poucos a sociedade volta a viver e reviver suas instituições e a Igreja Católica, que foi, ao longo da ditadura, "a voz dos que não podiam falar", saiu do estágio principal, retorna à sua função de formadora da fé, "anunciar sempre e por toda a parte os princípios morais, mesmo referentes à ordem social, e pronunciar-se a respeito de qualquer questão humana, enquanto o exigirem os direitos fundamentais da pessoa humana ou a salvação das almas". ${ }^{58}$ Entretanto, o tempo do enfrentamento político passou, embora ainda permaneça em alguns clérigos e leigos. 


\title{
Notas
}

\author{
${ }^{11}$ BOTAS, Paulo Cezar Loureiro. A Bênção de Abril. "Brasil Urgente", memória e engajamento católico no \\ Brasil 1963-64. Petrópolis: Vozes, 1983. \\ ${ }^{2}$ ALVES, Márcio Moreira. A Igreja e a política no Brasil. São Paulo: Brasiliense, 1979. \\ ${ }^{3}$ SERBIN, Kenneth. Diálogos na Sombra: bispos e militares, tortura e justiça social na ditadura. Trad. Carlos
}

Eduardo Lins da Silva. São Paulo: Companhia das Letras, 2001.

${ }^{4}$ SCOTT, Mainwaring. Igreja Católica e política no Brasil, 1916 -1985. Trad. Heloísa Braz de Oliveira. São Paulo: Brasiliense, 1989.

${ }^{5}$ BRESSER-PEREIRA, Carlos. As Revoluções Utópicas. Petrópolis: Editora Vozes, 1979.

${ }^{6}$ BEOZZO, Pe. José Oscar. Igreja do Brasil: de João XXIII a João Paulo II, de Medellín a Santo Domingo. Petrópolis: Vozes, 1993.

${ }^{7}$ PAZ, Jailson Souza. Cristãos Comunistas uma só defesa: história da Comissão de Justiça e Paz da arquidiocese de Olinda e Recife (1977-1980). Dissertação de Mestrado em História, UFPE, Recife, 2005, mimeo.

${ }^{8}$ Essa é a posição do historiador Antonio Villa em seu livro Ditadura à brasileira, recentemente publicado.

9 "É impossível negar os fatos." Disponível em: <https://apublica.org/2019/03/boris-fausto-sobre-o-golpe-de64-e-impossivel-negar-os-

fatos/?fbclid=IwAR2U0TMGumzvjAV8EKOFCMNNSldTVLI91m2314Eble2zKnb8KIe7ugxUATs\#.XJ5KtI6N X1A.facebook >

${ }^{10}$ A Comissão Nacional definiu como acidental a morte do ex-presidente, enquanto que a Comissão Municipal de São Paulo afirma o assassinato. Historiadores terão largo trabalho no futuro.

${ }^{11}$ Veja-se, por exemplo, a historiografia que foi produzida no bicentenário da Revolução Francesa. Aniversários são sempre emotivos, historiadores são homens de seu tempo e, por maior esforço que seja realizado, a sua obra terá sempre a marca do seu tempo, de sua formação, de sua classe social, de sua história pessoal, daí a diversidade de narrativas a cada geração de historiadores.

${ }^{12}$ SOLÉ, Jacques. A revolução Francesa em questões. Trad. Alda Porto e Marcos Santarrita. Rio de Janeiro: Jorge Zahar Editor. 1989. [11]

${ }^{13}$ CORREIA, Plínio de Oliveira. Reforma agrária questão de consciência, teve a colaboração de Dom Geraldo de Proença Sigaud (bispo de Diamantina, MG), Dom Antonio Castro Maia (bispo de Campos, RJ) e do economista Luiz Mendonça de Freitas. SILVA, Felipe Domingues da. Cruzados do século XX: o movimento tradição, família e propriedade (TFP): origens, doutrinas e práticas (1960-1970). Dissertação de Mestrado em História. Recife: UFPE 2009. Mimeo.

${ }^{14}$ Edgar Carone publicou pela DIFEL, vários volumes -sete - sobre a República, na década de 1970, com documentos, primários e secundários, sacralizando uma historiografia que nega uma das principais instituições formadoras do Brasil.

${ }^{15}$ A Comissão de Estudos de História da Igreja na América Latina foi criada em 1973, no Peru, e veio a ser conhecida no Brasil após a publicação da História da Igreja no Brasil Tomo II/I, coordenado por Eduardo Hoornaert. Essa coleção tem sido apresentada pelas editoras Vozes e Paulinas. São três volumes, sendo o primeiro dedicado à Época colonial, o segundo ao Império e o terceiro à República.

${ }^{1616}$ Embora não haja nenhum documento explicitando essa ordenação, pois a CNBB havia sido recentemente criada e os bispos atuavam ainda de maneira isolada, podemos verificar essa intenção, nas ações do bispo auxiliar do Rio Grande do Norte, Dom Eugênio Sales, e em Pernambuco, como citado a seguir, criação do SORPE. Veja o depoimento do padre Crespo ao CPDOC.

${ }^{17}$ Após a Segunda Guerra Mundial, a vitória contra o fascismo/nazismo não criou um mundo de paz, mas a polarização política entre duas potências: Estados Unidos da América do Norte e a União das Repúblicas Socialistas Soviéticas, gerando uma situação e tensão conhecida como Guerra Fria. Mas também veio o fenômeno da Descolonização da Ásia e da África, a compreensão da pobreza a que estavam submetidos muitos povos. Os blocos haviam definido seus espaços de atuação, mas os novos países assumiam protagonismos pondo em risco o equilíbrio desejado pelas potências. No Caribe, Cuba afronta os EUA e recebe apoio da URSS, e fez com que a América Latina passasse a ser vista como território a ser preservado para o Ocidente. O suicídio de Getúlio Vargas é um momento traumático dessa tensão de um país que deseja alavancar-se, mas encontra resistências internas que são acompanhadas por interesses externos. Com a eleição de Juscelino Kubitschek, seu governo renovador vê-se forçado a compreender a necessidade de atuar nas áreas mais atrasadas na chegada à 
modernidade. Embora não compreenda a necessidade de modificar as relações estruturais do mundo rural, viu-se na contingência de criar a Superintendência do Desenvolvimento da Amazônia - SUDAM, e a Superintendência do Desenvolvimento do Nordeste - SUDENE. Também a Igreja passa a agir de maneira nova, repensando a sua atuação tradicional e começa a ver os deserdados da América como sua área de atuação.

${ }^{18}$ Entre 1949 e 1962, a Igreja Católica criou, em Pernambuco, as dioceses de Caruaru, Afogados da Ingazeira e Palmares.

${ }^{19}$ Sociedade hierarquizada e de governo monárquico clerical, desde o final do século XIX, enquanto a cúpula da Igreja Católica Romana condenava o mundo moderno, setores do laicato buscavam uma maneira de manter-se no mundo dessacralizado que se formava. O jovem padre Joseph Cardjin dedicava-se a formar católicos para atuar em seu local de trabalho, donde veio a se formar a Juventude Operária Católica. A igreja buscava uma forma de agir no mundo onde o padre não chegava, essa foi a Ação Católica, fundada pelo papa Pio XI.

${ }^{20} \mathrm{O}$ modelo italiano percebia e realizava a sua ação separando os jovens por idade e sexo, enquanto o modelo belga-francês compreendia a realidade por ocupações profissionais e classe. Os jovens operários reuniam-se para refletir a sua ação no mundo e o método previa três momentos o Ver, o Julgar e Agir. Este veio a se tornar o método utilizado posteriormente pelas Comunidades Eclesiais de Base, nos anos de 1970.

${ }^{21}$ OLIVEIRA, Samuel Severino Silva Rodrigues da. A Cruzada São Sebastião e as favelas do Rio de Janeiro. $\quad$ ANPUH, 2012. Disponível em: < http://www.encontro2012.mg.anpuh.org/resources/anais/24/1340668954_ARQUIVO_OLIVEIRA,Samuel.ACr uzadaSaoSebastiaoEnviado.pdf> Acesso em: 24/abr/2014

${ }^{22}$ CRESPO, Enes Paulo. Paulo Crespo (depoimento, 1978). Rio de Janeiro, CPDOC, 1990. 46 p. dat. FUNDAÇÃO GETÚLIO VARGAS, CENTRO DE PESQUISA E DOCUMENTAÇÃO DE HISTÓRIA CONTEMPORÂNEA DO BRASIL (CPDOC).

${ }^{23}$ Padre Moisés Bernadino Lindoso $(1922$ - 2008) foi assistente da Ação Católica e, durante muitos anos, vigário da Igreja de São José Operário, na área industrial do município do Cabo de Santo Agostinho, chegou à arquidiocese de Olinda e Recife em $1964 . \quad$ Disponível em: <https://tribunapopular.wordpress.com/2008/07/24/pe-moises-lindoso-um-exemplo-de-vida/> Acesso em: $01 / \mathrm{abr} / 2019$

${ }^{24}$ Interessante que esse acontecimento, a morte de Dom Carlos Coelho e o lapso até a posse de Dom Hélder como arcebispo, fez com que a Igreja Católica não estivesse presente na grande concentração ocorrida em 8 de abril, organizada pelo movimento Marcha com Deus pela Família, em agradecimento ao movimento militar. A única autoridade religiosa a fazer-se presente oficialmente foi um pastor da Igreja Presbiteriana. A respeito da participação das igrejas nas comemorações pela vitória do movimento de 31 de março de 1964, ver a tese doutoral de Márcio Vilela Ananias, DISCURSOS E PRÁTICAS DA IGREJA PRESBITERIANA DO BRASIL DURANTE AS DÉCADAS DE 1960 E 1970: DIÁlOGOS ENTRE RELIGIÃO E POLÍTICA, apresentada no PPG de História da UFPE, 2014. Ver especialmente o capítulo 6.

${ }^{25} \mathrm{Na}$ década de cinquenta ocorreu um debate público entre um grupo de católicos que recusava atender a orientação do arcebispo na questão de eleitora. Ver SILVA, Severino Vicente da. Entre o Tibre e Capibaribe, os limites da igreja progressista na arquidiocese de Olinda e Recife. Recife: Editora Universitária UFPE; Olinda: Editora Reviva, 2005.

${ }^{26}$ Dom Hélder, Pastor e Profeta. São Paulo: Edições Paulinas. Neste livro apresento e comento vários discursos e homilias de Dom Hélder, inclusive a sua homília de posse na Arquidiocese.

${ }^{27}$ Ainda no Vaticano e pouco antes do Concílio Vaticano II ser encerrado, ocorreu reunião da CNBB que elegeu a nova direção da entidade, ficando à frente dela os setores conservadores liderados pelo Cardeal Agnelo Rossi, de São Paulo.

${ }^{28}$ Interessante análise do documento encontra-se em Carlos Bresser-Pereira.

${ }^{29}$ Fizeram parte da AP José Serra, Aldo Arantes, Haroldo Lima, Herbert José de Souza (Betinho). FranzWilheim Heimer era a vertente protestante.

${ }^{30}$ Pacto assinado por quarenta bispos na catacumba Domitila, pelo qual se comprometiam a levar uma vida de pobreza e não usar os símbolos de poder - Dom Antônio Fragoso, Crateús, CE; Dom Francisco Austregésilo, Afogados da Ingazeira, PE; Dom João Batista Mota de Albuquerque, Vitória; Dom Jorge Marcos, Santo André SP; Dom José Maria Pires, João Pessoa, PB, Dom Luiz Gonzaga Fernandes, Vitória ES e Campina Grande PB; Dom Henrique Golland Trindade, Botocatu, SP; Dom Hélder Câmara, auxiliar do RJ e Arcebispo de Olinda e Recife. O que foi este Pacto pode ser encontrado em diversas publicações, inclusive em https://noticias.uol.com.br/internacional/ultimas-noticias/2018/11/16/o-que-foi-o-pacto-das-catacumbas-quemudou-os-rumos-da-igreja-catolica.htm 
${ }^{31}$ Esta é uma evolução terminológica e programática que ocorre desde Medellín até a Conferência de Santo Domingo.

${ }^{32}$ Título que lhe foi dado pelo governador Carlos Lacerda e popularizado nas crônicas de Nelson Rodrigues.

${ }^{33}$ CASTRO, Gustavo. As comunidades do Dom. Recife: Editora Fundação Joaquim Nabuco, 1987.

${ }^{34}$ SILVA, Hilda Elaine Barros da. DINAMISMO E DEVOÇÃO: A ATUAÇÃO DE D. HELDER CÂMARA NA OPERAÇÃO ESPERANÇA ( 1965 - 1987 ). TCC. Departamento de História da UFPE. 2006.

${ }^{35}$ Posteriormente, João Francisco de Souza veio a ser professor da UFPE, com atuação na Prefeitura da Cidade do Recife, como diretor da Fundação Guararapes.

${ }^{36}$ Caso de Tibúrcio Santos e Custódio Amorim, com atuação em Nova Descoberta, bairro da periferia da zona norte da cidade do Recife, uma região de morros.

${ }^{37}$ É o caso de Severino Vicente da Silva, sequestrado em agosto de 1973 e liberado apenas no final de outubro do mesmo ano. Severino foi sequestrado juntamente com José Nivaldo Junior, também professor de história. José Nivaldo Junior, membro do Partido Comunista Revolucionário, foi ouvido pela comissão da Verdade Dom Hélder Câmara, do estado de Pernambuco, mas desconsiderou ouvir Severino Vicente da Silva, apesar de ele ter sido citado por José Nivaldo Junior, talvez por não ser filiado a nenhuma corrente partidária.

${ }^{38}$ Estive presente e atuei com palavras no palanque nessas duas manifestações.

39 SILVA, Severino Vicente da. Entre o Tibre e o Capibaribe, os limites da igreja progressista na arquidiocese de recife. 2. Ed. Recife: Editora UFPE, 2014. [174]

${ }^{40}$ CUNHA, Diogo Arruda Carneiro da. ESTADO DE EXCEÇÃO, IGREJA CATÓLICA E REPRESSÃO: o assassinato do padre Antonio Henrique Pereira da Silva Neto. Dissertação de Mestrado, UFPE-CFCH, Recife, 2007.

${ }^{41}$ A historiografia tem repetido o que foi escrito por jornalistas no calor da hora: que o padre Henrique era secretário e auxiliar direto de Dom Hélder, sem jamais ter sido apresentado um só documento que comprove esta afirmação, e jamais será apresentado pois ele jamais exerceu esta função de secretário. Quanto a ser auxiliar do bispo, todo padre incardinado em uma diocese é auxiliar do bispo, de acordo com os Cânones 273e seguintes do Código de Direito Romano. A informação de que Padre Antonio Henrique era secretário e braço direito de Dom Hélder jamais foi desmentida, pois não era do interesse da diocese, além do que uma negativa dessa informação poderia causar desinteresse pelo caso.

42 Após esse atentado, a UEP entrou em processo de desintegração, tendo deixado de existir em 1984 e ressurgido em 2005.

${ }^{43}$ A ACO foi criada em 1962, em encontro nacional da Juventude Operária Católica - JOC, com o objetivo de atender aos operários casados que já não podiam manter-se na JOC e precisavam de um acompanhamento de sua fé.

${ }^{44}$ Jornal Diário da Noite, 03 de agosto de 1967.

45 Jornal do Commercio, 28 de agosto de 1967.

${ }^{46}$ Hoje, além de ter seu nome em uma rua no bairro da Iputinga, o Padre Romano Zuffery é também uma praça no bairro operário de Jardim São Paulo, no Recife. Disponível em: <http://www.cpvsp.org.br/upload/periodicos/pdf/PCONSPE111988046.pdf>

47 PILETTI, Nelson; PRAXEDES, Walter. Dom Hélder Câmara, entre o poder e a profecia. São Paulo: Editora Ática, 1997.

${ }^{48}$ Foi preso no dia 29 de agosto de 1973, o estudante de teologia Severino Vicente da Silva, que era animador da Pastoral da Juventude da Arquidiocese e do Regional CNBB Nordeste II, ficou no DOI-CODI até 26 de outubro de 1972.

49 Esses são os signatários do documento: Pernambuco: Dom Hélder Câmara e Dom Lamartine, da Arquidiocese de Olinda e Recife; Dom Severino Mariano de Aguiar, da Diocese de Pesqueira; Dom Francisco Austregésilo de Mesquita, da Diocese de Afogados da Ingazeira; Maranhão: Dom João da Motta e Albuquerque e Dom Manoel Edmilson da Cruz, arcebispo e biso auxiliar da Arquidiocese de São Luia; Dom Rino Carlesi, da Diocese de Balsas; Dom Pascasio Rettler, da Diocese de Bacabal; e Dom Francisco Hélio Campo, de Viana; Paraíba: Dom José Maria Pires, da Arquidiocese da Paraíba, e Dom Manoel Pereira Costa, da Diocese de Campina Grande; Ceará: Dom Antônio Batista Fragoso, bispo de Crateús; Sergipe: Dom José Brandão de Castro, da Diocese de Propriá. Superiores religiosos: Frei Walfrido Mohn, provincial dos Franciscanos de Recife, Pernambuco; Pe. Hidenburgo Santana, provincial dos Jesuítas do Nordeste, Recife, Pernambuco; Pe. Gabriel Hofstede, provincial dos Redentoristas, Recife, Pernambuco; Dom Timóteo Amoroso Anastácio, Abade do Mosteiro de São Bento, Bahia; e Pe. Tarcisio Botturi, vice-provincial dos Jesuítas da Bahia.

${ }^{50}$ CALADO, Alder Júlio Ferreira. Eu ouvi os clamores de meu povo: um documento profético no auge da ditadura empresarial-militar, no Brasil. In: Consciência Net. Disponível em: <http://www.consciencia.net/euouvi-os-clamores-do-meu-povo-um-documento-profetico-publicado-no-auge-da-ditadura-empresarial-militarno-brasil/> 
51 Disponível em: <http://ultimosegundo.ig.com.br/brasil/brasil-reconhece-assassinato-politico-de-sacerdoteconsiderado-martir/n1237591362093.html> Visualizado em: 30//dez/2017.

52 SILVA, Júlio Reinaux Freitas. O Replicar dos Sinos: a expulsão do Padre Vito Miracapillo do Brasil. Recife, 2002, Mestrado em História UFPE-CFCH. Orientador: Sylvana Maria Brandão de Aguiar. $\mathrm{n}^{\circ}$ de pág.114

${ }^{53}$ Reginaldo Veloso abandonou o presbitério e atualmente é animador do Movimento de Trabalhadores Cristãos - MTC, sucessor da ACO. Embora ainda ligado à Igreja Católica, o MCT define-se de maneira mais ampla e ecumênica.

${ }^{54}$ PAZ, Jailson Souza. Cristãos e Comunistas uma só defesa: história da comissão de justiça e paz da arquidiocese de Olinda e Recife (1977- 1980). Dissertação de Mestrado, UFPE-CFCH, Recife, 2005. (mimeo).

55 SILVA, Severino Vicente da. Entre o Tibre e o Capibaribe: os limites da Igreja progressista na arquidiocese de Olinda e Recife. Recife: Editora Universitária UFPE; Editora Associação Reviva, 2011.

${ }^{56}$ A Comissão de Justiça e Paz da Arquidiocese de Olinda e Recife foi restabelecida pelo Arcebispos Dom Fernando Saburido.

${ }^{57}$ SERBIN, Kenneth. Diálogos na Sombra: bispos e militares, tortura e justiça social na ditadura. Trad. Carlos Eduardo Lins da Silva.São Paulo: Companhia das Letras, 2001.

${ }^{58}$ Código De Direito Canônico. São Paulo: Edições Loyola, 2002. Cânone 747.

\section{Referências Bibliográficas}

ALVES, Márcio Moreira. A Igreja e a política no Brasil. São Paulo: Brasiliense, 1979. BEOZZO, Pe. José Oscar. Igreja do Brasil: de João XXIII a João Paulo II, de Medellín a Santo Domingo. Petrópolis: Vozes, 1993

BOTAS, Paulo Cezar Loureiro. A Bênção de Abril. "Brasil Urgente", memória e engajamento católico no Brasil 1963-64. Petrópolis: Vozes, 1983.

Brasil reconhece assassinato político de sacerdote considerado mártir. In: Último Segundo. Disponível em: <http://ultimosegundo.ig.com.br/brasil/brasil-reconhece-assassinato-politicode-sacerdote-considerado-martir/n1237591362093.html> Acessado em: 30/dez/2017.

BRESSER-PEREIRA, Liz Carlos. As Revoluções Utópicas. v. 1. Petrópolis: Editora Vozes, 1979.

CALADO, Alder Júlio Ferreira. Eu ouvi os clamores de meu povo: um documento profético no auge da ditadura empresarial-militar, no Brasil. In: Consciência Net. Disponível em: $<$ http://www.consciencia.net/eu-ouvi-os-clamores-do-meu-povo-um-documento-profeticopublicado-no-auge-da-ditadura-empresarial-militar-no-brasil/ $>$

DABAT, Christine. Mulheres no movimento revolucionário chinês (1839-1949). Recife: Editora Universitária - UFPE, 2006.

Código De Direito Canônico. São Paulo: Edições Loyola, 2002.

CASTRO, Gustavo. As comunidades do Dom. Recife: Editora Fundação Joaquim Nabuco, 1987.

COELHO, Fernando. Direita, volver: o golpe de 64 em Pernambuco. Recife: Bagaço, 2004

CUNHA, Diogo Arruda Carneiro da. ESTADO DE EXCEÇÃO, IGREJA CATÓLICA E REPRESSÃO: o assassinato do padre Antonio Henrique Pereira da Silva Neto. Dissertação de Mestrado, UFPE-CFCH, Recife, 2007.ax

FAUSTO, Boris. O Golpe de 64: É impossível negar os fatos. In: Publica. Disponível em: $<$ https://apublica.org/2019/03/boris-fausto-sobre-o-golpe-de-64-e-impossivel-negar-osfatos/?fbclid=IwAR2U0TMGumzvjAV8EKOFCMNNSldTVLI91m2314Eble2zKnb8KIe7ug xUATs\#.XJ5KtI6NX1>A.facebook Acessado em: 01/abr/2019.

MORAIS, J. F. Regis de. Os bispos e a política no Brasil: pensamento social da CNBB. São Paulo: Cortez: Autores Associados, 1982. 
OLIVEIRA, Samuel Severino Silva Rodrigues da. A Cruzada São Sebastião e as favelas do Rio de Janeiro. ANPUH, 2012.

PAZ, Jailson Souza. Cristãos e Comunistas uma só defesa: história da comissão de justiça e paz da arquidiocese de Olinda e Recife (1977- 1980). Dissertação de Mestrado, UFPE-CFCH, Recife, 2005. (mimeo).

PILETTI, Nelson; PRAXEDES, Walter. Dom Hélder Câmara, entre o poder e a profecia. São Paulo: Editora Ática, 1997.

SCOTT, Mainwaring. Igreja Católica e política no Brasil, 1916 -1985. Trad. Heloísa Braz de Oliveira. São Paulo: Brasiliense, 1989.

SERBIN, Kenneth. Diálogos na Sombra: bispos e militares, tortura e justiça social na ditadura. Trad. Carlos Eduardo Lins da Silva. São Paulo: Companhia das Letras, 2001.

SILVA, Felipe Domingues da. Cruzados do século XX: o movimento tradição, família e propriedade (TFP): origens, doutrinas e práticas (1960-1970). Dissertação de Mestrado em História. Recife: UFPE 2009. (mimeo).

SILVA, Hilda Elaine Barros da. Dinamismo e devoção: a atuação de d. Helder Câmara na operação esperança (1965 - 1987 ). TCC em História. Recife: Departamento de História da UFPE, 2006. (mimeo).

SILVA, Júlio Reinaux Freitas. O Replicar dos Sinos: a expulsão do Padre Vito Miracapillo do Brasil. Dissertação de Mestrado em História, Recife, UFPE-CFCH, 2002. (mimeo).

SILVA, Severino Vicente da. Entre o Tibre e o Capibaribe: os limites da Igreja progressista na arquidiocese de Olinda e Recife. Recife: Editora Universitária UFPE; Editora Associação Reviva, 2011.

SILVA, Severino Vicente da. Entre o Tibre e o Capibaribe: os limites da Igreja progressista na arquidiocese de Olinda e Recife. 2. Ed. Recife: Editora Universitária UFPE; Editora Associação Reviva, 2014.

SOLÉ, Jacques. A Revolução Francesa em questões. Trad. Alda Porto e Marcos Santarrita. Rio de Janeiro: Jorge Zahar Editor, 1989.

VILLA, Marco Antonio. Ditadura à Brasileira, 1964-1985, a democracia golpeada à esquerda e à direita. São Paulo: LEYA, 2014.

VILELA, Márcio Ferreira Ananias. DISCURSOS E PRÁTICAS DA IGREJA PRESBITERIANA DO BRASIL DURANTE AS DÉCADAS DE 1960 E 1970: DIÁLOGOS ENTRE RELIGIÃO E POLÍTICA, apresentada no PPG de História da UFPE, 2014.

Disponível

em:

<http://www.cpvsp.org.br/upload/periodicos/pdf/PCONS30/PE111988046.pdf>

Acessado

em: $30 /$ dez/2017 